\section{Paolo Martelletti}

P. Martelletti (凶)

Department of Internal Medicine,

Headache Center,

Second School of Medicine,

Sant'Andrea Hospital,

Via di Grottarossa 1035-1039,

I-00189 Rome, Italy

e-mail: paolo.martelletti@uniroma1.it

Tel.: 06-80345622

Fax: 06-80345323

\title{
The unfinished war
}

Editorial interest in headache and particularly in migraine continues to grow. More and more frequently the Editors of several general and specialist journals, though not so much the sector journals, publish interesting papers that hold an undisputed appeal for the readership. As research groups with an interest in headache disorders have grown, research into the basic science of headaches has grown scarce and moved away from the institutional journals of the sector.

The "triptan war", an expression often used in literature [1], is the name given to the intense research efforts to distinguish the various triptans and to identify the best triptans molecular for migraine therapy. The triptan war is fought out with brilliant and imposing comparative meta-analyses [2], innovative pharmacoeconomic studies [3] and the latest strategies to evaluate the recovery in quality of life parameters [4]. While these efforts continue to bring enormous benefits to migraine sufferers in terms of evidence regarding the most effective treatments, the least side effects, and the least likelihood of relapse, it may also have reduced researchers' drive to look into the more obscure corners of migraine, cluster headache and tension headaches. In brief, the real war is still going on.
An analysis of the triptan era of the last decade and its continued expansion revealed a full presence in renowned journals in the headache field and showed that it has not encouraged, but in fact inhibited, the proposal and study of innovative physiopathological mechanisms which could lead to complementary or alternative pharmacological approaches [5]. So while the availability of triptans is inevitably reaching a saturation point, doctors are left with prophylactic pharmaceuticals for headache disorders which are out-of-date, difficult to manage and, today, practically in disuse $[6,7]$. These pharmaceuticals however, have entered clinical use and are considered effective following an empirical phase of clinical application [8].

The current explosive phase of social medicine being applied to headaches sheds a little light on the problem. Headache disorders have recently acquired a clinical dignity that was previously unheard of. Just an year ago, the World Health Organization (WHO) published its 2001 Health Report in which migraines were ranked twelfth for women of all ages (2.0\%) and nineteenth for both sexes $(1.4 \%)$ as the leading cause of years of life lived with a disability [9]. Migraine ranked higher than asthma for women and higher than cerebrovascular disorders 
and diabetes mellitus for both sexes [9]. However, once we have achieved a full understanding of headache's impact on the individual and on society as a whole, have gained the certainty of new and brilliant guidelines for treating headaches [10], will be able to recommend triptans with the best cost effectivenes value, and will have taught our patients how to live with their headaches using the best triptan in the best possible way, we will still need to pose the question: Is the war over?

And our answer will have to be no, unfortunately no. Unless we have new, effective, safe and manageable therapeutic strategies for headache prophylaxis, our work will not be done. We therefore need to redirect cultural attention, scientific interest and economic resources towards this new undefined frontier in order to be able to finally bring this war to an end. Journals should provide scientific information and stimulate researchers to work on current issues. I firmly believe that new joint ventures between academic research centres and the pharmaceutical industry can lay the foundation for new exciting war paths towards the creation of pharmaceuticals for the prophylaxis of headache disorders.

\section{References}

1. Ferrari MD (1998) Migraine. Lancet 351:1043-1051

2. Ferrari MD, Roon KI, Lipton RB, Goadsby PJ (2001) Oral triptans (serotonin 5-HT(1B/1D) agonists) in acute migraine treatment: a meta-analysis of 53 trials. Lancet 358:1668-1675

3. Folino-Gallo P, Palazzo F, Stirparo G, De Filippis S, Martelletti P (2002) Utilizations and price of triptans in the European countries. Cephalalgia 22[Suppl 1]:21-22
4. Hu XR, Markson LE, Lipton RB, Stewart WF, Berger ML (1999) Burden of migraine in the United States. Disability and economic costs. Arch Int Med 159:813-818

5. - Headache (2002) 42:1-84

6. Fanciullacci M, Franchi G, Sicuteri F (1976) Ergotamine and methysergide as serotonin partial agonists in migraine. Headache 16:226-231

7. Solomon GD (1982) Calcium channel blockers in migraine. Lancet 2:162
8. Markley HG (1991) Verapamil in migraine prophylaxis: mechanisms and efficacy. Am J Med 90(5A):48S-53S

9. - (2001) The World Health Report 2001. Mental Health: New Understanding, New Hope. World Health Organization, Geneva (http://www.who.int/whr/index.htm, viewed 18 March 2002)

10. - (2001) Diagnostic and therapeutic guidelines for migraine and cluster headache. J Headache Pain 2:105-192 